\title{
Forced oscillation technique for determination of resistance to breathing in children
}

\author{
J. J. COGSWELL \\ From the Respiratory Unit, The Hospital for Sick Children, Great Ormond Street, London
}

\begin{abstract}
Cogswell, J. J. (1973). Archives of Disease in Childhood, 48, 259. Forced oscillation technique for determination of resistance to breathing in children. A method for measuring total respiratory resistance $\left(R_{T}\right)$ using a forced oscillation technique was applied to children between 3 and 12 years of age. $R_{T}$ at midinspiration was higher than airway resistance (Raw) measured on the same children by total body plethysmography. Normal $R_{T}$ values were compared with results in children with asthma and cystic fibrosis. It is suggested that the technique could have a wider application in the assessment of airway obstruction in children.
\end{abstract}

Many of the techniques for the measurement of airway obstruction which have been developed for investigation of adults have been successfully applied to children. Indirect methods of measuring flow resistance, i.e. peak expiratory flow rate and timed forced expiratory volume, are perhaps the simplest and most convenient way of assessing obstructive airways disease. However, these simple tests do require the co-operation of the patient and they are in part effort dependent, which limits their application to children under 5 years.

Direct measurements of airflow resistance have been done in children with a pneumotachograph at the mouth and a balloon in the oesophagus to record transpleural pressure changes (Helliesen et al., 1958; Engstrom, Karlberg, and Swarts, 1962). These techniques required sedation and the passage of an oesophageal balloon. Airway resistance measurements have also been made by total body plethysmography in co-operative children (Briscoe and DuBois, 1958; Zapletal et al., 1969; Weng and Levison, 1969). Total body plethysmography is not easy to carry out in children under 6 years, or in very sick children. The need to develop a method for the direct measurement of airflow resistance in unsedated young children without requiring oesophageal balloons or body plethysmography prompted the adaptation of the forced oscillation technique. The method was first described by DuBois et al. (1956b), and has been successfully applied to measure total respiratory resistance in animals (Brody et al., 1956), human

Received 7 August 1972. adults (Fisher, DuBois, and Hyde, 1968; Goldman et al., 1970), and babies (Wohl, Stigol, and Mead, 1969).

The purpose of this paper is to describe the use of the forced oscillation technique in children. The results are compared in the same child with airway resistance measurements (Raw) obtained by body plethysmography. Normal data for total respiratory resistance $\left(R_{T}\right)$ are presented, and use of the technique in the assessment of children with obstructive airways disease is described.

\section{Method}

Theory. Total respiratory resistance $\left(R_{T}\right)$ was derived from flow and pressure relations recorded at the mouth of the subject during the application of a sine wave of airflow superimposed at a frequency approximating to the natural frequency of the respiratory system.

When a sine wave of airflow is applied to the tracheobronchial tree the transthoracic pressure changes induced are related to the total impedance of the system. Impedance comprises the vector sum of effective resistance and effective reactance. Reactance is the sum of elastic and mass inertial properties which, for a sine wave superimposed on a linear system, is $180^{\circ}$ out of phase. At low frequencies elastic impedance dominates, while at high frequencies inertial impedance dominates. At a certain intermediate frequency, the resonant frequency, elastic and inertial impedance are of equal magnitude, and opposite in sign. The resonant frequency is found where the pressure and flow are in phase, and their relation describes the flow resistance of the respiratory system. In our experiments, the sine wave frequency selected was 5 to $7 \mathrm{~Hz}$. This was found to be the natural frequency of the bronchial tree 
in healthy children, and is similar to the natural frequency in adults (Fisher et al., 1968). Because it was found difficult to find resonance in children with obstructive airway disease, the same frequency was selected for all measurements, and no attempt was made to 'tune' to each patient.

Precise tuning was not necessary if measurements were made between certain points of the cycle-namely, the points of zero volume acceleration at the extremes of flow. Between such points elastic and inertial properties do not contribute to the pressure differences, which relate only to flow resistance (Goldman et al., 1970).

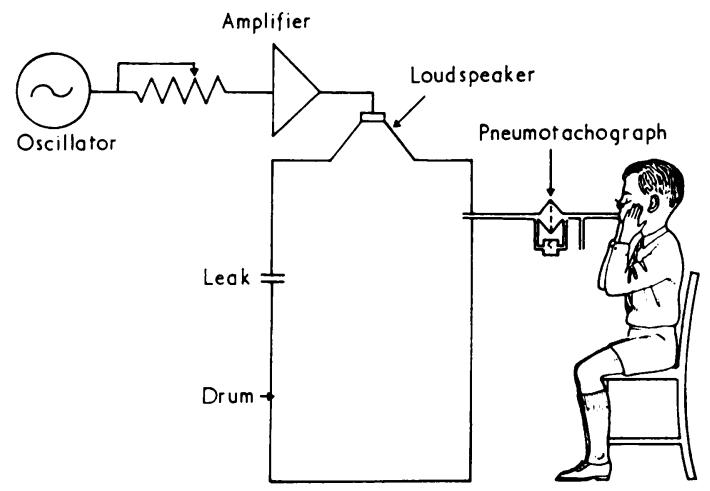

FIG. 1.-Schematic representation of apparatus.

Apparatus. Fig. 1 shows a block diagram of the apparatus. The child sits by the equipment and breathes quietly through a pneumotachograph via a soft rubber mouthpiece. The pneumotachograph was mounted in a cone-shaped assembly with a side opening to record airway pressure close to the mouth.

Mouth pressure was sensed with respect to atmosphere by an ether strain gauge transducer. Airflow was measured by a Fleisch (no. 3) pneumotachograph connected to an isovolume differential transducer of high sensitivity. * After amplification, the flow and pressure signals were recorded simultaneously on a direct writing recorder. $\dagger$

The oscillations were provided by a loudspeaker mounted on a rigid drum connected to the mouthpiece assembly by a wide bore tube. The loudspeaker was driven by a low frequency sine wave oscillator and power amplifier, which was linear down to $2 \mathrm{~Hz}$. The system acted in the same way as a sine wave pump, and allowed the frequency and amplitude of the oscillations to be varied.

Other tests of ventilatory function. Normal children, and those with asthma and cystic fibrosis, had other tests of ventilatory function performed on the same laboratory visit.

The peak expiratory flow. rate (PFR) was determined

«Elema Schonander Type EMT 32.

tDevices equipment. by the Wright peak flow meter (Wright and McKerrow, 1959). After explanation and practice, the best of 3 consistent blows was recorded.

The vital capacity (VC) and forced expiratory volume in 0.75 second (FEV 0.75 ) was determined on a reverse plethysmograph system (Milner, 1971).

Thoracic gas volume (TGV) and airway resistance were measured by total body plethysmography. A constant volume total body plethysmograph was used, designed on the principles described by DuBois, Botelho, and Comroe (1956a). The modifications for paediatric usage incorporated a total volume of $600 \mathrm{l}$. and walls constructed of transparent acrylic plastic. The instrument was used to measure thoracic gas volume and airway resistance. Measurements were made with the child panting at 90 breaths per minute while the cheeks were supported. Airways resistance was measured on inspiration at flow rates from zero to $0.251 . / \mathrm{sec}$.

Technique of $\mathbf{R}_{\mathrm{T}}$ measurement. Calibration was carried out before each experiment. Mouth pressure was calibrated by a water manometer connected to the ether strain gauge transducer. Calibration of airflow through the pneumotachograph was performed with a rotameter using moist room air at $22^{\circ} \mathrm{C}$.

In practice, the measurement of $R_{T}$ could be carried out in less than 3 minutes, but attention to detail was essential. The child sat by the equipment and a leakfree seal at the mouth was achieved with a soft rubber mouthpiece. The child was asked to breathe quietly while supporting the cheeks with both hands. The nose was held, or clipped off. When the child was breathing in a relaxed way the oscillator was turned on at $5 \mathrm{~Hz}$, and the gain on the amplifier was adjusted so that flow wave deflections of 0.251 ./sec were obtained. 4 to 5 tidal breaths were adequate for analysis.

Analysis of the record. A typical trace is shown in Fig. 2. The volume trace is obtained by electronic integration of flow, and it allows each phase of the respiratory cycle to be identified. In children, the most satisfactory point at which to measure $R_{T}$ was at midinspiration. $\mathbf{R}_{\mathbf{T}}$ results presented in this paper were all made at the midinspiratory point $\left(R_{T Y}\right)$, and each result is the mean of 3 readings made on different breaths. Only satisfactory sinusoidal pressure and flow waves were selected for analysis. Artefacts, due to leaks at the mouth or complete closure of the glottis, could be identified and were discarded. Very rapid (over $60 / \mathrm{min}$ ) respiratory rates prohibited accurate analysis.

\section{Subjects}

Normal children. 204 normal children took part in the study. Consent from parents and school authorities was obtained. Normal children under 5 years were studied at an adjacent nursery school using portable apparatus. The majority of normal children over 5 years came from schools in the London area. Others were relatives of medical staff, and some were children who had been admitted to hospital before 


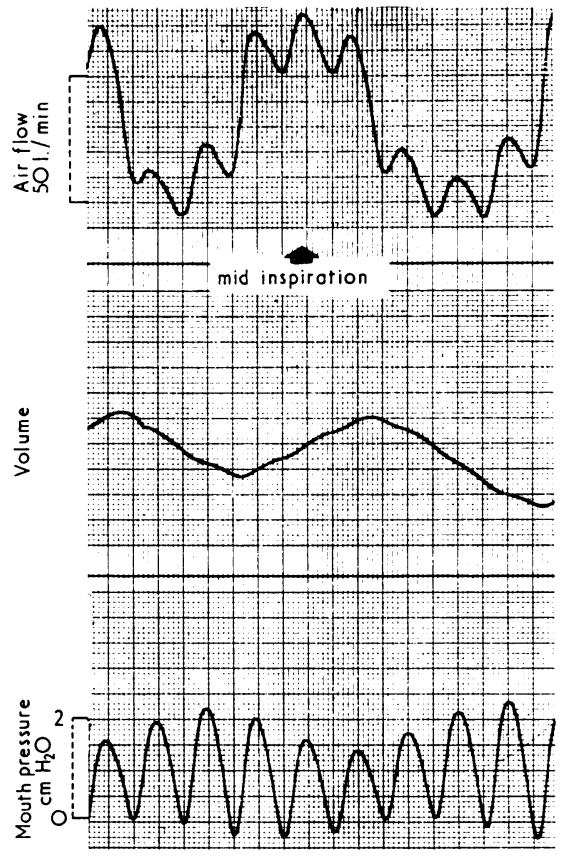

FIG. 2.-Record obtained during measurement of total respiratory resistance in a normal boy of 12 years. The trace shows the flow and mouth pressure to be 'in phase' at $5 \mathrm{~Hz}$. Total respiratory resistance was derived from the pressure/flow relation at the midinspiratory point.

minor operations. No child with a history of asthma or lung disease was included.

At each study a record was made of the child's name, age, sex, height, weight (without shoes and outdoor clothes), and arm span. The mean values of the physical measurements are shown in Table $\mathrm{I}$ in which the children are divided into $10 \mathrm{~cm}$ height groups. The average height and weight of each group was appropriate for age (Tanner, Whitehouse, and Takaishi,
1966), except that an excess of tall 12-year-old children was included.

Children with asthma. 42 children with asthma were studied by the forced oscillation technique. The ages ranged from 2 years 10 months to 12 years 1 month. All had chronic asthma of sufficient severity to require outpatient hospital management. No child was receiving steroid drugs. The clinical severity of their disease varied widely; some were symptom free at the time of study and others had a definite wheeze. The asthmatic children were selected for lung function studies, which included the forced oscillation technique, by the outpatient clinician.

Children with cystic fibrosis. 44 children with cystic fibrosis were studied by the forced oscillation technique. All had had the diagnosis confirmed by sweat electrolyte analysis. The youngest child examined was aged 3 years 1 month. All the children were referred from the outpatient department of the hospital which they attended on a regular basis. The degree of lung involvement was variable.

\section{Results}

Reproducibility. Duplicate measurements of total respiratory resistance $\left(R_{T}\right)$ were made in normal 8-year-old children with 1 hour's interval between the 2 determinations. The data are presented in Table II. The mean SD of duplicate measurements was 0.56 . The mean \% SD of repeated measurements was $12 \%$.

It was not possible to sustain interest in very young children to obtain repeated measurements. In 2 co-operative children, aged 8 and 5 years, studies of $R_{T}$ were determined repeatedly over a period of 1 hour. Results indicating the change in $R_{T}$ obtained are shown in Fig. 3.

Normal children. 204 normal children aged 3 to 12 years were studied to establish the accepta-

TABLE I

Physical characteristics of 204 normal children

\begin{tabular}{|c|c|c|c|c|c|c|}
\hline $\begin{array}{l}\text { Height } \\
\text { group }\end{array}$ & $\begin{array}{l}\text { Height range } \\
(\mathrm{cm})\end{array}$ & No. & $\begin{array}{c}\text { Mean age } \\
(y \mathbf{y})\end{array}$ & $\begin{array}{l}\text { Mean height } \\
(\mathrm{cm})\end{array}$ & $\begin{array}{l}\text { Mean weight } \\
(\mathrm{kg})\end{array}$ & $\begin{array}{l}\text { Mean span } \\
(\mathrm{cm})\end{array}$ \\
\hline $\begin{array}{l}\text { I } \\
\text { II } \\
\text { III } \\
\text { IV } \\
\text { V } \\
\text { VI } \\
\text { VII }\end{array}$ & $\begin{array}{c}90-99 \\
100-109 \\
110-119 \\
120-129 \\
130-139 \\
140-149 \\
150-159\end{array}$ & $\begin{array}{l}11 \\
40 \\
33 \\
44 \\
38 \\
24 \\
14\end{array}$ & $\begin{array}{l}3 \cdot 10 \\
4 \cdot 6 \\
5 \cdot 11 \\
7 \cdot 9 \\
9 \cdot 8 \\
11 \cdot 3 \\
11 \cdot 9\end{array}$ & $\begin{array}{r}97 \\
105 \\
115 \\
125 \\
135 \\
143 \\
154\end{array}$ & $\begin{array}{l}15 \cdot 0 \\
18 \cdot 0 \\
21 \cdot 2 \\
25 \cdot 9 \\
30 \cdot 1 \\
38 \cdot 0 \\
47 \cdot 8\end{array}$ & $\begin{array}{r}95 \\
103 \\
112 \\
125 \\
135 \\
145 \\
153\end{array}$ \\
\hline
\end{tabular}


TABLE II

Reproducibility. Duplicate observations of total respiratory resistance made in 8 healthy 8-year-old boys

\begin{tabular}{|c|c|c|c|c|c|c|c|c|}
\hline Subject & $\mathbf{A}$ & $\mathbf{B}$ & C & D & $\mathbf{E}$ & $\mathbf{F}$ & G & $\mathbf{H}$ \\
\hline $\begin{array}{l}\text { First measurement } \mathbf{R}_{\mathbf{T}} \\
\text { Second measurement } \mathbf{R}_{\mathbf{T}} \\
\text { Mean } \\
\text { SD } \\
\% \text { SD }\end{array}$ & $\begin{array}{r}4 \cdot 4 \\
6 \cdot 5 \\
5 \cdot 5 \\
1 \cdot 5 \\
28 \cdot 0\end{array}$ & $\begin{array}{l}4 \cdot 4 \\
4 \cdot 8 \\
4 \cdot 6 \\
0 \cdot 3 \\
6 \cdot 0\end{array}$ & $\begin{array}{l}4 \cdot 4 \\
4 \cdot 7 \\
4 \cdot 5 \\
0 \cdot 2 \\
4 \cdot 7\end{array}$ & $\begin{array}{r}5 \cdot 8 \\
4 \cdot 5 \\
5 \cdot 1 \\
0 \cdot 9 \\
18 \cdot 0\end{array}$ & $\begin{array}{l}6 \cdot 8 \\
6 \cdot 3 \\
6 \cdot 5 \\
0 \cdot 3 \\
5 \cdot 4\end{array}$ & $\begin{array}{r}3 \cdot 0 \\
3 \cdot 8 \\
3 \cdot 4 \\
0 \cdot 6 \\
16 \cdot 7\end{array}$ & $\begin{array}{r}3 \cdot 6 \\
2 \cdot 9 \\
3 \cdot 2 \\
0 \cdot 5 \\
15 \cdot 3\end{array}$ & $\begin{array}{l}5 \cdot 0 \\
4 \cdot 7 \\
4 \cdot 8 \\
0 \cdot 2 \\
4 \cdot 3\end{array}$ \\
\hline
\end{tabular}

Note: The second measurement was made 1 hour after the first. Each measurement is the mean $\mathbf{R}_{\mathbf{r}}$ of 3 readings at the midinspiratory point.

$\mathrm{R}_{\mathrm{x}}$, total respiratory resistance $\left(\mathrm{cmH}_{2} \mathrm{O} / 1\right.$ per sec).

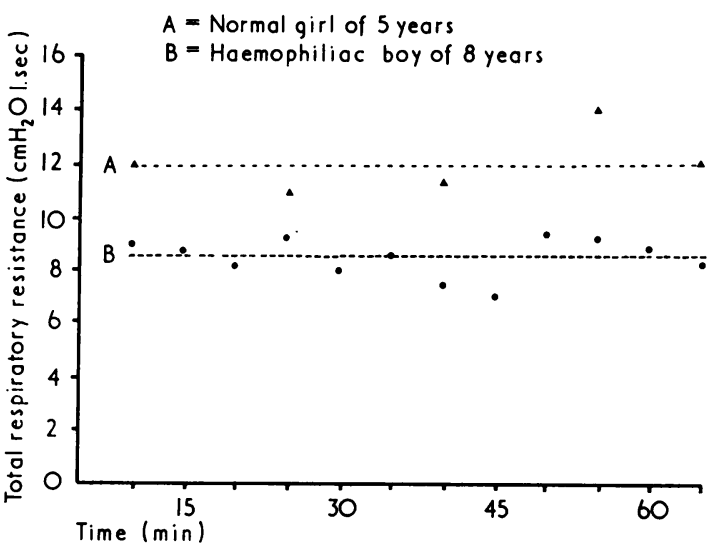

FIG. 3.-Repeated total respiratory resistance $\left(\mathbf{R}_{\mathrm{T}}\right)$ determinations in 2 children over a 60-minute period.

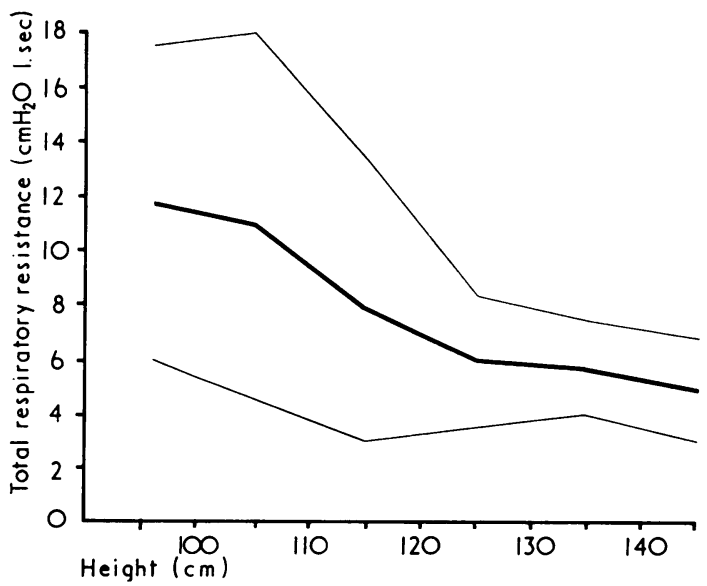

FIG. 4.-Total respiratory resistance $\left(\mathbf{R}_{\mathbf{T}}\right)$ plotted against height in 204 normal children. The thick line indicates the mean $\mathbf{R}_{\mathbf{T}}$ of each $10 \mathrm{~cm}$ height group. The thin lines represent $2 S D$ s of the mean. bility of the technique and to provide normal data for $R_{T}$ in this age group.

Results are expressed graphically as a function of height in Fig. 4. The graph indicates the mean $R_{\mathrm{T}}$ of each $10 \mathrm{~cm}$ height group together with 2 SDs. 106 of these normal children were old enough to co-operate in plethysmographic determination of airway resistance at the same visit. The mean data determined by both methods are expressed as a function of height in Fig. 5.

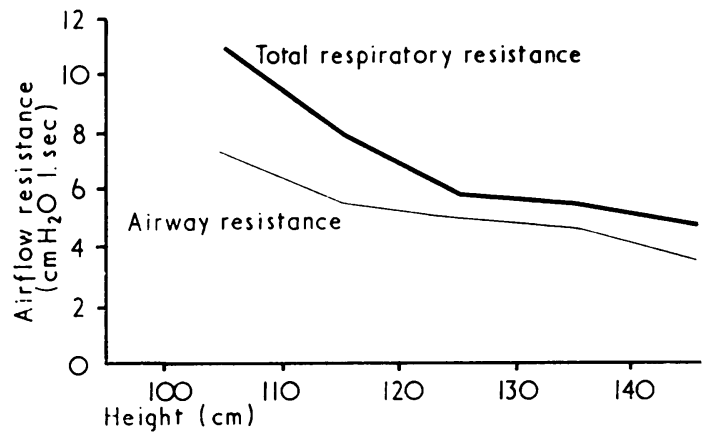

FIG. 5.-Total respiratory resistance $\left(\mathrm{R}_{\mathrm{T}}\right)$ measured by the forced oscillation technique and airway resistance (Raw) measured plethysmographically plotted against height in 106 normal children. The thick line indicates the mean $\mathbf{R}_{\mathrm{T}}$ of each $10 \mathrm{~cm}$ height group, and the thin line indicates the mean Raw of each $10 \mathrm{~cm}$ height group.

Children with asthma. 42 children with asthma were examined by the forced oscillation technique. Superimposed oscillation frequency of 5 to $6 \mathrm{~Hz}$ used for the normal subjects was unchanged, but precise resonance was not present in all cases. $R_{T}$ measurements were made at midinspiration. At the same laboratory visit other tests of ventilatory function were carried out, and results are presented in Table III.

Results of $R_{T} /$ height are expressed graphically 
TABLE III

Children with asthma

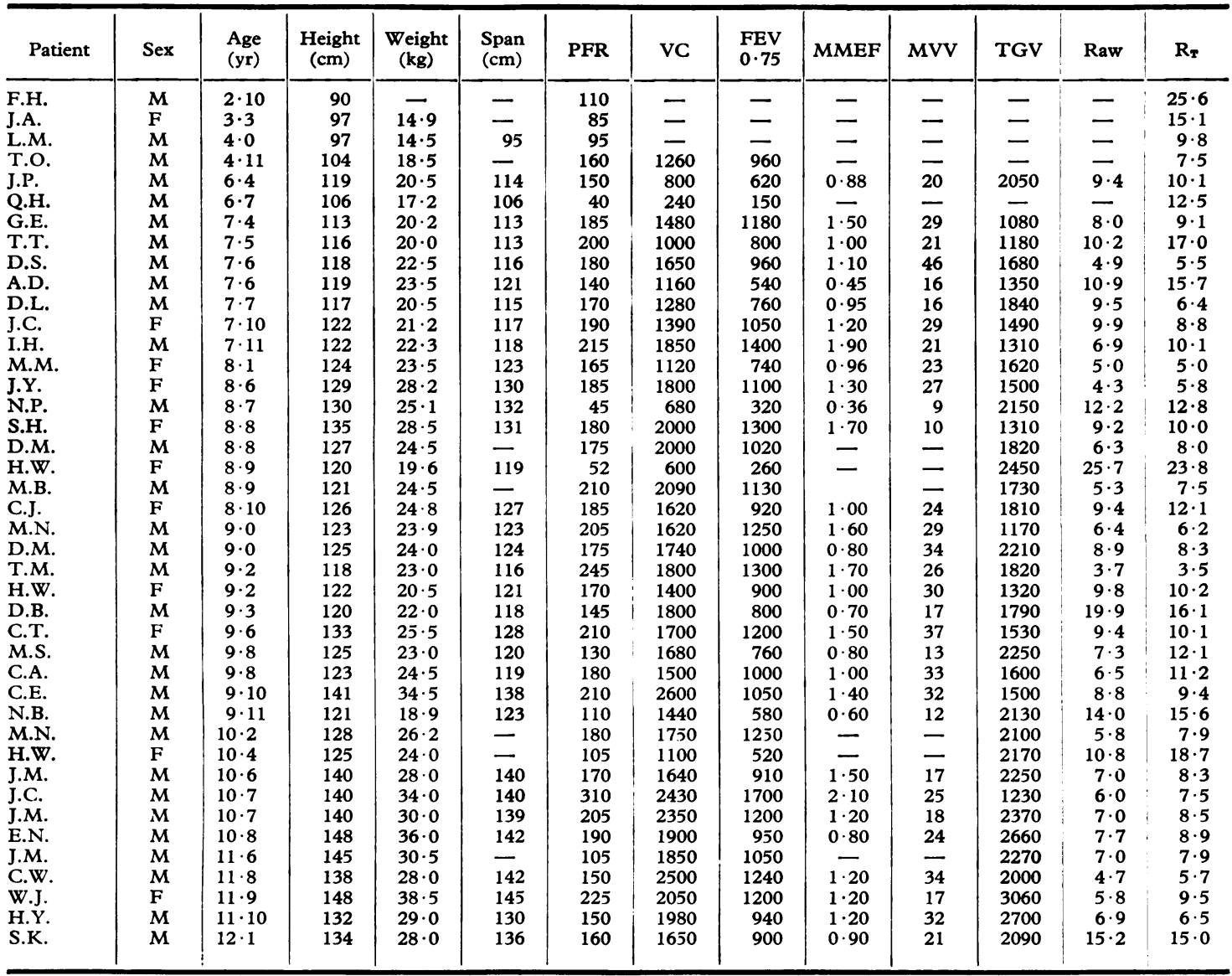

PFR, peak flow rate (1./min); VC, vital capacity (ml); FEV 0.75, forced expiratory volume at 0.75 second (ml); MMEF, maximum mid-

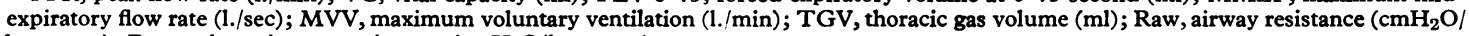
1. per sec); $\mathrm{R}_{\mathrm{T}}$, total respiratory resistance $\left(\mathrm{cmH}_{2} \mathrm{O}\right.$ !l. per sec).

in Fig. 6, which also shows the mean and $\pm 2 \mathrm{SD}$ for the normal schoolchildren. 23 asthmatic children had $R_{T}$ values above +2 SD of the mean for healthy school children.

Children with cystic fibrosis. 44 studies by oscillation technique were carried out in patients with cystic fibrosis. 24 studies were carried out on 18 children under 6 years. These children were too young to co-operate in spirometry or plethysmography.

Results of $R_{T}$ measurements in the children with CF are presented in Tables IV and V. Results of $\mathbf{R}_{T}$ /height for all the children with $C F$ are plotted in Fig. 7. The mean and 2 SDs for the healthy schoolchildren is indicated. 6 children with CF had $R_{T}$ values in excess of 2 SDs above the mean.

Results of serial observations in 5 patients with CF over a 16-month period are shown in Fig. 8.

Clinical details of these children are summarized here:

M.P. A 4-year-old boy (height $103 \mathrm{~cm}$ at first study). $\mathrm{CF}$ diagnosed at 4 months. Symptom free, and chest clinically normal. Minimal change on chest $x$-ray. The final $\mathbf{R}_{\mathrm{T}}$ determination was made at the time of an exacerbation with radiological evidence of a chest infection.

S.F. A 4-year-old girl (height $102 \mathrm{~cm}$ at first study). CF diagnosed at 3 months. Asymptomatic, and chest 
TABLE IV

Children with cystic fibrosis under 6 years of age

\begin{tabular}{|c|c|c|c|c|c|c|}
\hline Patient & Sex & $\begin{array}{l}\text { Age } \\
(y r)\end{array}$ & $\begin{array}{l}\text { Height } \\
\text { (cm) }\end{array}$ & $\begin{array}{l}\text { Weight } \\
\text { (kg) }\end{array}$ & PFR & $\mathbf{R}_{\mathbf{T}}$ \\
\hline $\begin{array}{l}\text { M.C. } \\
\text { T.C. } \\
\text { H.G. } \\
\text { R.L. } \\
\text { T.B. } \\
\text { A.C. } \\
\text { V.T. } \\
\text { T.W. } \\
\text { S.F. } \\
\text { M.P. }\end{array}$ & $\begin{array}{l}\text { M } \\
\text { M } \\
\text { F } \\
\text { F } \\
\text { M } \\
\text { F } \\
\text { M } \\
\text { M } \\
\text { F } \\
\\
\text { M } \\
\\
\text { M } \\
\text { F } \\
\text { M } \\
\text { F } \\
\text { M } \\
\text { M } \\
\text { F } \\
\text { M }\end{array}$ & $\begin{array}{l}3 \cdot 1 \\
3 \cdot 3 \\
3 \cdot 3 \\
3 \cdot 5 \\
3 \cdot 6 \\
3 \cdot 6 \\
4 \cdot 6 \\
4 \cdot 0 \\
4 \cdot 0 \\
4 \cdot 0 \\
4 \cdot 9 \\
5 \cdot 5 \\
4 \cdot 0 \\
4 \cdot 9 \\
4 \cdot 11 \\
4 \cdot 2 \\
4 \cdot 6 \\
4 \cdot 7 \\
4 \cdot 9 \\
4 \cdot 11 \\
5 \cdot 0 \\
5 \cdot 6 \\
5 \cdot 2 \\
5 \cdot 6\end{array}$ & $\begin{array}{r}89 \\
93 \\
92 \\
101 \\
95 \\
89 \\
97 \\
97 \\
111 \\
102 \\
103 \\
108 \\
103 \\
105 \\
109 \\
93 \\
98 \\
103 \\
108 \\
106 \\
109 \\
111 \\
111 \\
116\end{array}$ & $\begin{array}{l}10 \cdot 9 \\
15 \\
13 \cdot 3 \\
19 \cdot 5 \\
11 \cdot 5 \\
10 \cdot 9 \\
15 \\
15 \cdot 7 \\
19 \cdot 5 \\
15 \cdot 6 \\
15 \cdot 5 \\
17 \\
18 \\
18 \\
19 \\
17 \\
14 \cdot 5 \\
18 \\
19 \\
16 \\
19 \\
20 \\
18 \cdot 5 \\
19 \cdot 7\end{array}$ & $\begin{array}{r}80 \\
40 \\
105 \\
175 \\
90 \\
110 \\
155 \\
105 \\
190 \\
150 \\
150 \\
155 \\
140 \\
130 \\
150 \\
150 \\
160 \\
170 \\
160 \\
180 \\
170 \\
170 \\
145 \\
200\end{array}$ & $\begin{array}{r}13 \cdot 8 \\
8 \cdot 2 \\
9 \cdot 0 \\
12 \cdot 5 \\
21 \cdot 1 \\
6 \cdot 8 \\
17 \cdot 0 \\
11 \cdot 0 \\
8 \cdot 2 \\
12 \cdot 7 \\
8 \cdot 5 \\
10 \cdot 0 \\
11 \cdot 6 \\
9 \cdot 5 \\
15 \cdot 0 \\
13 \cdot 5 \\
11 \cdot 0 \\
11 \cdot 0 \\
8 \cdot 8 \\
9 \cdot 5 \\
9 \cdot 2 \\
15 \cdot 0 \\
7 \cdot 0 \\
6 \cdot 3\end{array}$ \\
\hline
\end{tabular}

PFR, peak flow rate $(1 . / \mathrm{min}) ; \mathrm{R}_{\mathrm{T}}$, total respiratory resistance $\left(\mathrm{cmH}_{2} \mathrm{O} / 1\right.$. per sec).

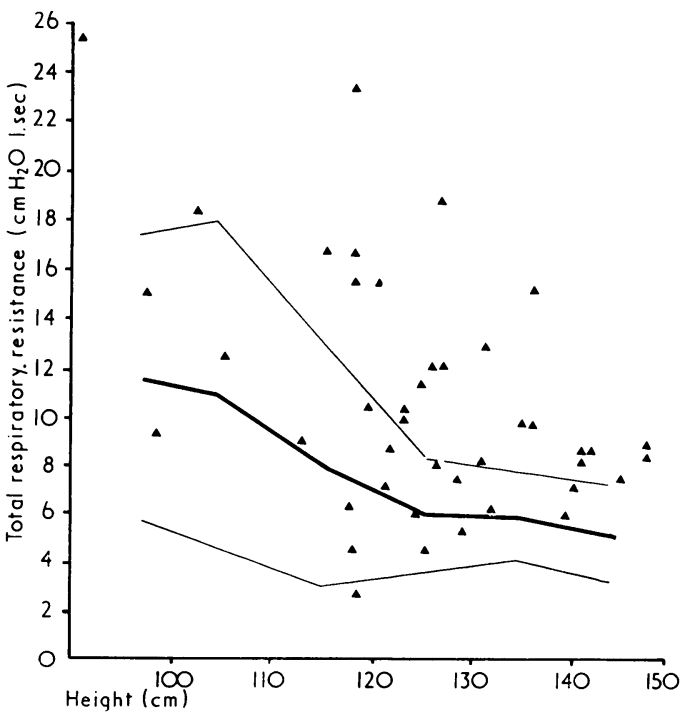

FIG. 6.-Total respiratory resistance $\left(\mathrm{R}_{\mathrm{T}}\right)$ in 42 children with asthina plotted as a function of height. The mean $\mathrm{R}_{\mathrm{T}} \pm 2 S D$ s for normal children is indicated.

clinically normal. Minimal chest $x$-ray changes. $R_{T}$ results remained within the normal range.

J.D. An 11-year-old girl (height $123 \mathrm{~cm}$ at first study). Productive cough and râles in all chest areas.

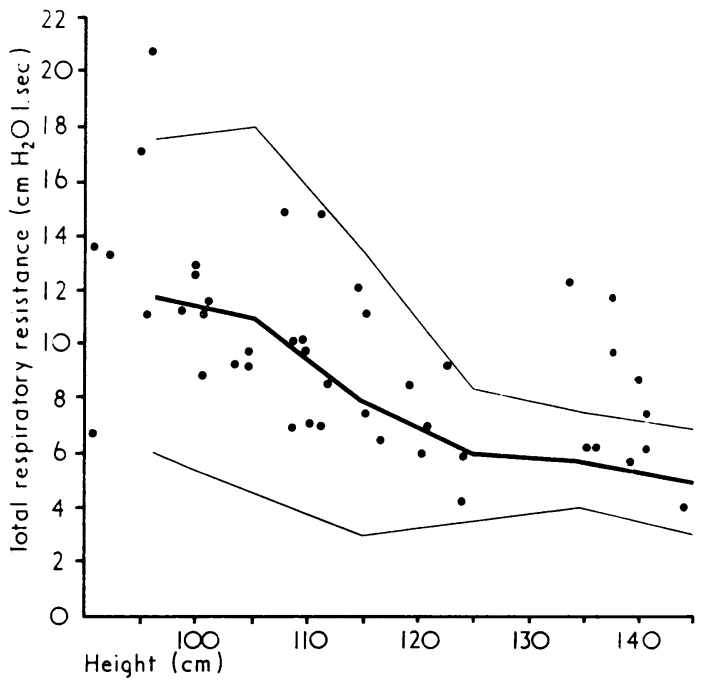

FIG. 7.-Total respiratory resistance $\left(\mathbf{R}_{\mathrm{T}}\right)$ in 44 children with cystic fibrosis plotted as a function of height. The mean $\mathrm{R}_{\mathrm{T}} \pm 2$ SDs for normal children is indicated.

Fingers clubbed. Chest $x$-ray showed advanced disease. Clinical course fluctuates. There were 2 exacerbations of chest infection in April 1971 and May 1972 , both associated with abnormal $R_{T}$ values.

P.B. A 13-year-old boy (height $160 \mathrm{~cm}$ at first study). 
TABLE V

Children with cystic fibrosis over 6 years of age

\begin{tabular}{|c|c|c|c|c|c|c|c|c|c|c|c|c|c|}
\hline Patient & Sex & $\begin{array}{l}\text { Age } \\
(y r)\end{array}$ & $\begin{array}{c}\text { Height } \\
\text { (cm) }\end{array}$ & $\begin{array}{l}\text { Weight } \\
\text { (kg) }\end{array}$ & $\begin{array}{l}\text { Span } \\
(\mathrm{cm})\end{array}$ & PFR & VC & $\begin{array}{l}\text { FEV } \\
0 \cdot 75\end{array}$ & MMEF & MVV & TGV & Raw & $R_{T}$ \\
\hline $\begin{array}{l}\text { A.T. } \\
\text { E.D. } \\
\text { P.B. } \\
\text { M.L. } \\
\text { C.D. } \\
\text { E.D. } \\
\text { P.B. } \\
\text { J.R. } \\
\text { M.L. } \\
\text { J.D. } \\
\text { T.P. } \\
\text { S.B. } \\
\text { H.W. } \\
\text { J.D. } \\
\text { C.H. } \\
\text { K.G. } \\
\text { J.K. } \\
\text { S.G. } \\
\text { C.H. } \\
\text { J.B. } \\
\text { C.H. } \\
\text { P.N. }\end{array}$ & $\begin{array}{l}\text { M } \\
\text { M } \\
M \\
F \\
F \\
M \\
M \\
M \\
F \\
F \\
M \\
M \\
F \\
M \\
F \\
F \\
M \\
M \\
M \\
M \\
F\end{array}$ & $\begin{array}{c}6 \cdot 0 \\
6 \cdot 6 \\
6 \cdot 6 \\
7 \cdot 1 \\
7 \cdot 3 \\
7 \cdot 4 \\
7 \cdot 6 \\
7 \cdot 6 \\
7 \cdot 6 \\
7 \cdot 7 \\
8 \cdot 4 \\
8 \cdot 5 \\
9 \cdot 0 \\
9 \cdot 2 \\
10 \cdot 4 \\
10 \cdot 4 \\
10 \cdot 4 \\
10 \cdot 11 \\
12 \cdot 9 \\
12 \cdot 10 \\
13 \cdot 9 \\
16 \cdot 6\end{array}$ & $\begin{array}{l}116 \\
116 \\
109 \\
118 \\
110 \\
121 \\
120 \\
116 \\
124 \\
123 \\
116 \\
123 \\
138 \\
132 \\
141 \\
136 \\
138 \\
140 \\
140 \\
136 \\
144 \\
145\end{array}$ & $\begin{array}{l}21 \cdot 6 \\
21 \cdot 5 \\
19 \cdot 5 \\
21 \cdot 0 \\
19 \cdot 0 \\
22 \cdot 0 \\
25 \cdot 0 \\
21 \cdot 5 \\
22 \cdot 5 \\
21 \cdot 0 \\
18 \cdot 7 \\
22 \cdot 7 \\
25 \cdot 5 \\
28 \cdot 0 \\
31 \cdot 5 \\
35 \cdot 5 \\
34 \cdot 4 \\
29 \cdot 0 \\
30 \cdot 0 \\
31 \cdot 5 \\
31 \cdot 8 \\
35 \cdot 5\end{array}$ & $\begin{array}{l}114 \\
119 \\
110 \\
\overline{118} \\
110 \\
122 \\
120 \\
118 \\
123 \\
140 \\
\overline{144} \\
- \\
\overline{140} \\
143 \\
137 \\
-\end{array}$ & $\begin{array}{l}170 \\
165 \\
170 \\
170 \\
180 \\
175 \\
170 \\
200 \\
175 \\
205 \\
210 \\
190 \\
140 \\
210 \\
190 \\
185 \\
300 \\
265 \\
220 \\
310 \\
195 \\
325\end{array}$ & $\begin{array}{l}1090 \\
1200 \\
1110 \\
1600 \\
1160 \\
1250 \\
1500 \\
1580 \\
1600 \\
1720 \\
1520 \\
1080 \\
1280 \\
1750 \\
1900 \\
1170 \\
2100 \\
2400 \\
1500 \\
1740 \\
1770 \\
2500\end{array}$ & $\begin{array}{r}840 \\
720 \\
850 \\
850 \\
920 \\
590 \\
840 \\
980 \\
670 \\
1180 \\
1080 \\
480 \\
640 \\
1100 \\
1400 \\
800 \\
1580 \\
1300 \\
1200 \\
1230 \\
1000 \\
2160\end{array}$ & $\begin{array}{c}-\overline{0.80} \\
\overline{0.90} \\
1.30 \\
\overline{-} \\
0.76 \\
1.10 \\
0.85 \\
1.50 \\
1.40 \\
0.50 \\
0.50 \\
- \\
2.00 \\
- \\
2.00 \\
1.40 \\
1.70 \\
1.40 \\
- \\
-\end{array}$ & $\begin{array}{l}\overline{23} \\
\overline{18} \\
21 \\
\overline{26} \\
25 \\
20 \\
26 \\
23 \\
21 \\
20 \\
35 \\
- \\
28 \\
24 \\
24 \\
53 \\
-\end{array}$ & $\begin{array}{c}1280 \\
1100 \\
- \\
1540 \\
1000 \\
1510 \\
1970 \\
1250 \\
1570 \\
1260 \\
1110 \\
1250 \\
2130 \\
1730 \\
1650 \\
1730 \\
1990 \\
2500 \\
1360 \\
2280 \\
2380 \\
1600\end{array}$ & $\begin{array}{r}11 \cdot 3 \\
7 \cdot 0 \\
8 \cdot 8 \\
6 \cdot 7 \\
7 \cdot 7 \\
7 \cdot 3 \\
10 \cdot 5 \\
3 \cdot 3 \\
6 \cdot 2 \\
7 \cdot 2 \\
6 \cdot 2 \\
11 \cdot 4 \\
6 \cdot 7 \\
4 \cdot 5 \\
7 \cdot 5 \\
4 \cdot 0 \\
6 \cdot 0 \\
6 \cdot 3 \\
5 \cdot 9 \\
3 \cdot 7 \\
3 \cdot 3\end{array}$ & $\begin{array}{r}12 \cdot 5 \\
7 \cdot 9 \\
7 \cdot 0 \\
8 \cdot 5 \\
7 \cdot 4 \\
7 \cdot 0 \\
6 \cdot 2 \\
11 \cdot 6 \\
5 \cdot 3 \\
4 \cdot 0 \\
9 \cdot 8 \\
9 \cdot 0 \\
10 \cdot 0 \\
12 \cdot 7 \\
6 \cdot 5 \\
6 \cdot 2 \\
6 \cdot 0 \\
7 \cdot 8 \\
8 \cdot 7 \\
6 \cdot 2 \\
4 \cdot 5 \\
4 \cdot 5\end{array}$ \\
\hline
\end{tabular}

PFR, peak flow rate (1./min); VC, vital capacity (ml); FEV 0.75, forced expiratory volume at 0.75 second (ml); MMEF, maximum midexpiratory flow rate (1./sec); MVV, maximum voluntary ventilation $(1 . / \mathrm{min})$; TGV, thoracic gas volume (ml); Raw, airway resistance $\left(\mathrm{cmH}_{2} \mathrm{O} / \mathrm{l}\right.$. per sec); $\mathrm{R}_{\mathrm{T}}$, total respiratory resistance $\left(\mathrm{cmH}_{2} \mathrm{O} / \mathrm{l}\right.$. per sec).

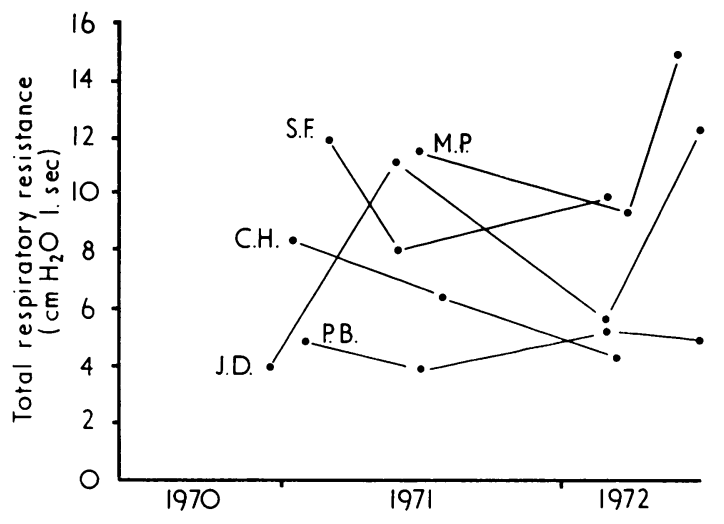

FIG. 8.- Serial studies of total respiratory resistance $\left(\mathbf{R}_{\mathrm{T}}\right)$ in 5 children with cystic fibrosis over a 16-month period.

Little clinical disability, except productive cough. Finger clubbing. Chest $x$-ray showed hyperinflation.

C.H. A 13-year-old boy (height $144 \mathrm{~cm}$ at first study). Chest infection was present at time of first study in January 1971, but no recurrence. He has a productive cough and râles in all chest areas. Chest $x$-ray showed moderately advanced disease.

Normal children, and children with asthma and cystic fibrosis, who were old enough to cooperate had whole body plethysmography performed

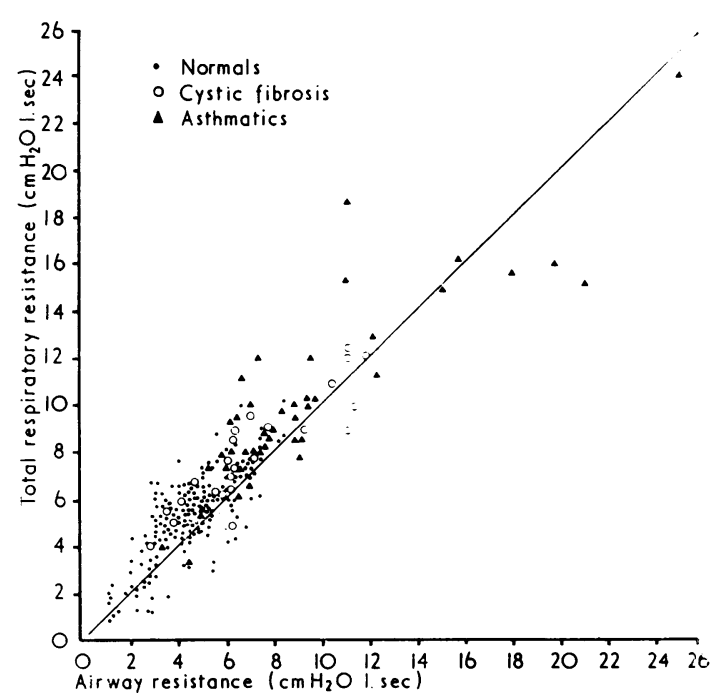

FIG. 9.-Total respiratory resistance plotted against airway resistance measured in the same child on the same visit. Normal children and children with obstructive airway disease are included. The straight line represents the line of identity.

at the same visit. The results of airway resistance (Raw) measured by this method, and $R_{\mathrm{r}}$ measured by the forced oscillation technique are expressed in Fig. 9. $R_{T}$ measured by forced oscillation was 
on average $30 \%$ higher than airway resistance measured plethysmographically in the same subject at comparable flow rates.

\section{Discussion}

The forced oscillation technique has been used to measure total respiratory resistance in adults (Fisher et al., 1968; Goldman et al., 1970) and babies (Wohl et al., 1969). Experience reported here indicates that the method is applicable to children between 3 and 12 years of age. The test is quick to carry out and satisfactory results can be obtained in children under 5 years, an age when other respiratory function tests are not well tolerated. A normal range of $R_{T}$ values is reported in healthy children. $R_{T}$ falls with increasing growth of the child. The scatter of normal values is high in the young children.

The technique is applicable to ill children, and causes no discomfort in a dyspnoeic child. Asthmatic children may have values of $R_{T}$ which are several times greater than the expected mean for healthy children of the same height. Many of the young patients with cystic fibrosis have $R_{T}$ values within the normal range. There is a tendency for $R_{T}$ to rise above normal with increasing age, or during exacerbations of chest infection.

Total respiratory resistance by the oscillation technique tends to be higher than airway resistance measured plethysmographically in the same child. There could be more than one reason for this. Airway resistance measured by body box does not include those components of resistance due to lung tissue and chest wall. Though measurements by both methods in each child were made at the same visit, they could not be performed on simultaneous breaths, nor at identical flow rates and lung volumes. The panting manoeuvre could not be used during forced oscillations, and it is possible that there was a contribution of resistance from the partially closed glottis during quiet inspiration. Finally, though the impedance of a healthy lung at resonant frequency does approximate to respiratory resistance (DuBois et al., 1956b), this may not be the case in diseased lungs where physical characteristics are unevenly distributed. It is not possible to exclude the possibility that reactance may be making a contribution to the observed measurements by the oscillation technique in sick children.

I am indebted to Professor D. Hull and Drs. A. P. Norman, A. D. Milner, and D. J. Hatch for their help in setting up the technique and preparing this manuscript. The author gratefully acknowledges financial support from the Asthma Research Council.

\section{REFERENCES}

Briscoe, W. A., and DuBois, A. B. (1958). The relationship between airway resistance, airway conductance and lung volume in subjects of different age and body size. Fournal of Clinical Investigation, 37, 1279.

Brody, A. W., DuBois, A. B., Nisell, O. I., and Engelberg, J. (1956). Natural frequency, damping factor and inertance of the chestlung system in cats. American fournal of Physiology, 186, 142.

DuBois, A. B., Botelho, S. Y., and Comroe, J. H. (1956a). A new method for measuring airway resistance in man using a body plethysmograph: values in normal subjects and in patients with respiratory disease. Fournal of Clinical Investigation, 35, 327.

DuBois, A. B., Brody, A. W., Lewis, D. H., and Burgess, B. F. (1956b). Oscillation mechanics of lungs and chest in man. fournal of Applied Physiology, 8, 587.

Engstrom, I., Karlberg, P., and Swarts, C. L. (1962). Respiratory studies in children. IX. Relationships between mechanical properties of the lungs, lung volumes and ventilatory capacity in healthy children 7 to 15 years of age. Acta Paediatrica, $51,68$.

Fisher, A. B., DuBois, A. B., and Hyde, R. W. (1968). Evaluation of the forced oscillation technique for the determination of resistance to breathing. Fournal of Clinical Investigation, 47, 2045.

Goldman, M., Knudson, R. J., Mead, J., Peterson, N., Schwaber, J. R., and Wohl, M. E. (1970). A simplified measurement of respiratory resistance by forced oscillation. Fournal of Applied Physiology, 28, 113.

Helliesen, P. J., Cook, C. D., Friedlander, L., and Agathon, S. (1958). Studies of respiratory physiology in children. I Mechanics of respiration and lung volumes in 85 normal children 5-17 years of age. Pediatrics, 22, 80 .

Milner, A. D. (1971). Assessment of respiratory function in childhood and infancy. In Recent Advances in Paediatrics, 4th ed. p. 217. Ed. by D. Gairdner and D. Hull. Churchill, London.

Tanner, J. M., Whitehouse, R. H., and Takaishi, M. (1966). Standards from birth to maturity for height, weight, height velocity, and weight velocity: British children, 1965. Archives of Disease in Childhood, 41, 613.

Weng, T. R., and Levison, H. (1969). Standards of pulmonary function in children. American Review of Respiratory Disease, 99, 879.

Wohl, M. E. B., Stigol, L. C., and Mead, J. (1969). Resistance of the total respiratory system in healthy infants and infants with bronchiolitis. Pediatrics, 43, 495.

Wright, B. M., and McKerrow, C. B. (1959). Maximum forced expiratory flow rate as a measure of ventilatory capacity. British Medical fournal, $2,1041$.

Zapletal, A., Motoyama, E. K., van de Woestijne, K. P., Hunt, V. R., and Bouhuys, A. (1969). Maximum expiratorv flowvolume curves and airway conductance in children and adolescents. Fournal of Applied Physiology, 26, 308.

Correspondence to Dr. J. J. Cogswell, The Hospital for Sick Children, Great Ormond Street, London WC1N 3JH. 